\title{
Insecticide residues cross-contamination of oilseeds during storage
}

\author{
Sylvie DAUGUET \\ CETIOM, Transformation et valorisation \\ des graines oléagineuses, \\ 11 rue Monge Parc Industriel \\ 33600 Pessac \\ <dauguet@cetiom.fr>
}

\begin{abstract}
Pesticide residues are found in oilseeds and crude oils: they are mainly organophosphate insecticides (pirimiphos-methyl, dichlorvos, malathion) used in empty storage facilities and for application to stored cereal grains. Even if pests are found in stored oilseeds, French regulation does not permit use of these insecticides on stored oilseeds, as they have affinity for these lipophilic subtances. These residues arise from cross-contamination during mechanical contact with storage bins and grain handling equipment, and not from illegal use. This uptake of insecticide residues from their storage environment by oilseeds can lead to levels that exceed regulatory limits. An investigation of 11 grain storage companies allowed us to follow the course of 27 sunflower seeds batches, from reception at the storage facilities to outloading. Samples from each of these batches, made at outloading, were analysed content for insecticide residues. Traceability of sunflower seeds established by storers allowed us to identify the origine of observed cross-contamination cases. Substances discovered were dichlorvos, pirimiphos-methyl and malathion (and chlorpyriphos-methyl in a single case). Pirimiphos-methyl was most commonly detected, but most cases of non-accordance with regulatory levels were observed with dichlorvos and malathion. Main cross-contamination hazard resulted from treatment of cereals at outloading, just before sunflower seeds were outloaded, especially when these cereals treatments were frequent on that elevator. Other situations led to cross-contaminations, but generally of lower levels: outloading of sunflower seeds after outloading of cereal that was treated at the reception, several weeks or months before; sunflower seeds stored in bin that contained previously treated cereal; empty bins and handling equipment treated before receipt of sunflower seeds.
\end{abstract}

Key words: oilseeds, insecticide, pesticide residues, storage, cross-contamination
Post-harvest insecticide residues are frequently found on oilseeds, at low levels. But, no insecticide is allowed to be applied directly to oilseeds during storage. Consequently, maximum residue levels (MRLs) allowed by European regulation are very low (mostly at the lower limit of analytical determination): $0,01 \mathrm{mg} / \mathrm{kg}$ for dichlorvos (still authorised during this study, but forbidden now), and $0,05 \mathrm{mg} / \mathrm{kg}$ for pirimiphos-methyl. No MRL exists for malathion, so it shouldn't be found beyond the analytical limit of quantification. These insecticide treatments are authorised on stored cereals and corn as a grain protectant, and on empty storage and handling equipment as a control agent for residual insect populations in empty granaries. Dichlorvos, malathion and pirimiphos-methyl were the substances most employed during this study (storage season 2006-2007, regulation changed later).

So, we can hypothesise that crosscontamination phenomena can exist, between these various kind of seeds, cereals and oilseeds, sharing the same grain handling and storage system. This phenomena has already been demonstrated in Canada on rapeseed [1-3], when empty bins are treated with organophosphorous insecticides (bromophos, malathion, fenitrothion). Canadian storers were warned that treating before storing rapeseed could lead to residues above the maximum allowable limits.

Uptake of pirimiphos-methyl by a single-layer of rapeseed or wheat on galvanized-steel surfaces was demonstrated and quantified in a laboratory study $[4,5]$. It was shown that, for small bins (less than 50 tons), it could lead to residues quantities above regulatory limits. But in big elevators, insecticide uptakes by seeds can also occur at other stages: conveying belts, handling of oilseeds after cereals had been treated in the same circuits, outloading bin, etc. so we cannot rule out either risk for grain storage companies.

In order to improve our knowledge about this post-harvest insecticide cross-contamination, especially in big elevators, an investigation was carried out with the collaboration of several French grain storage companies. Real cases were observed, with an accurate traceability of sunflower seeds lots all along their route inside storage facilities (from receipt to outloading) to find where the insecticides were taken up by the oilseeds.

Results presented in this article concern the first year of the investigation, concentrating on sunflower seeds during the storage season 20062007. This investigation will continue on rapeseed during the next storage season.

\section{Materials and methods}

The process adopted for this survey was: - Identifying with storage operators sunflower lots that could be "traced" (recording of each step from receipt to outloading): 11 grain storage companies agreed to collaborate, and allowed us to follow 27 sunflower seeds bins. These companies were situated throughout the sunflower crop area.

- Making a mean sample from each batch representative of sunflower seeds arriving at the storage facilities ("first sample") and preserving it. These samples were analysed only when residues were found in the final sample, in order to know if contamination occurred before receipt of grain. These "first samples" were analysed for 4 batches of seeds. 
Table 1. Analytical results (expressed in $\mu \mathrm{g} / \mathrm{kg}$ ) on the 28 final samples.

\begin{tabular}{|c|c|c|c|c|c|c|c|c|c|c|}
\hline & LQ & MRL & Mean & Median & $\begin{array}{l}\text { Standard } \\
\text { deviation }\end{array}$ & $\begin{array}{c}\text { 9th } \\
\text { decile }\end{array}$ & Maxi & $\begin{array}{c}\text { \% samples } \\
\geq \text { LD }\end{array}$ & $\begin{array}{c}\text { \% samples } \\
\geq \mathbf{L Q}\end{array}$ & $\begin{array}{c}\text { \% samples } \\
\text { > MRL }\end{array}$ \\
\hline Dichlorvos & 10 & 10 & 21 & 0 & 79 & 27 & 422 & $32 \%$ & $29 \%$ & $21 \%$ \\
\hline Pirimiphos-methyl & 10 & 50 & 19 & 5 & 55 & 29 & 295 & $61 \%$ & $39 \%$ & $4 \%$ \\
\hline Chlorpyriphos méthyl & 10 & 50 & 0 & 0 & & & 10 & $4 \%$ & $4 \%$ & $0 \%$ \\
\hline Malathion & 10 & - & 8 & 0 & 25 & 17 & 125 & $18 \%$ & $18 \%$ & $18 \%$ \\
\hline Sum of residues & & & 48 & 12 & 102 & 120 & 427 & & & \\
\hline
\end{tabular}

LQ: limit of quantification; LD: limit of detection; MRL: maximum residues limits in sunflower seeds. Sum of residues: a value of $5 \mu \mathrm{g} / \mathrm{kg}$ is given when a substance is detected but below the limit of quantification, and zero value if under the limit of detection.

- Making a mean sample representative of outloaded sunflower seeds, "final sample", when the traced lot is commercialized (from one to eight months after harvesting). These "final samples" were always analysed. In one case, we had 2 samples for one sunflower batch, so that we analysed 28 final samples. The sampling method used was based on a standard method (moving seeds, for contaminant with heterogeneous distribution determination, prEN ISO 24333:2006): 25 elementary samples for 500 tons evenly distributed during the outloading (one elementary sample each 20 tons). This method was usually well observed by the commercial operators.

- Filling a questionnaire called "traceability" which recorded each step from receipt to outloading. Operators had to indicate if treatments were applied on empty bins or handling equipment, or if cereals were treated at their receipt or outloading and if these cereals used the same conveyer circuit inside the storage facilities just before sunflower seeds.

- Determination of insecticide residues in all the "final samples": the analytical laboratory of ITERG conducted theses determinations, using the "common method" developed since three years by a group of about twenty French laboratories (public and private) coordinated by CETIOM and ITERG: Soxhlet extraction of oil with hexane (NF EN ISO 659) was followed by analysis of organophosphorous residues by gaseous chromatography with detection NPD.

\section{Results}

Twenty-eight samples were analyzed (table 1, figure 1).

The insecticides used on cereals and for storage facilities treatment were detected: dichlorvos, pirimiphos-methyl, malathion and chlorpyriphos-methyl (only 1 case). Most commonly detected substance was pirimiphos-methyl: detected in $61 \%$ of samples and quantified in $39 \%$ of samples. But, malathion and dichlorvos were more frequently above MRL: $21 \%$ and $18 \%$ of cases respectively.

On the whole, final samples were slightly contaminated as half of them contained less than
$12 \mu \mathrm{g} / \mathrm{kg}$ of insecticide residues (sum of residues median), and $90 \%$ of them contained less than $120 \mu \mathrm{g} / \mathrm{kg}$ (sum of residues $9^{\text {th }}$ decile). Analytical results for each substance (figures 2-4): Pirimiphos-methyl - Only one sample had a very high level $(T 12: 295 \mu \mathrm{g} / \mathrm{kg})$. The other samples were always below the MRL: 4 between 20 and $50 \mu \mathrm{g} / \mathrm{kg}$, 12 between

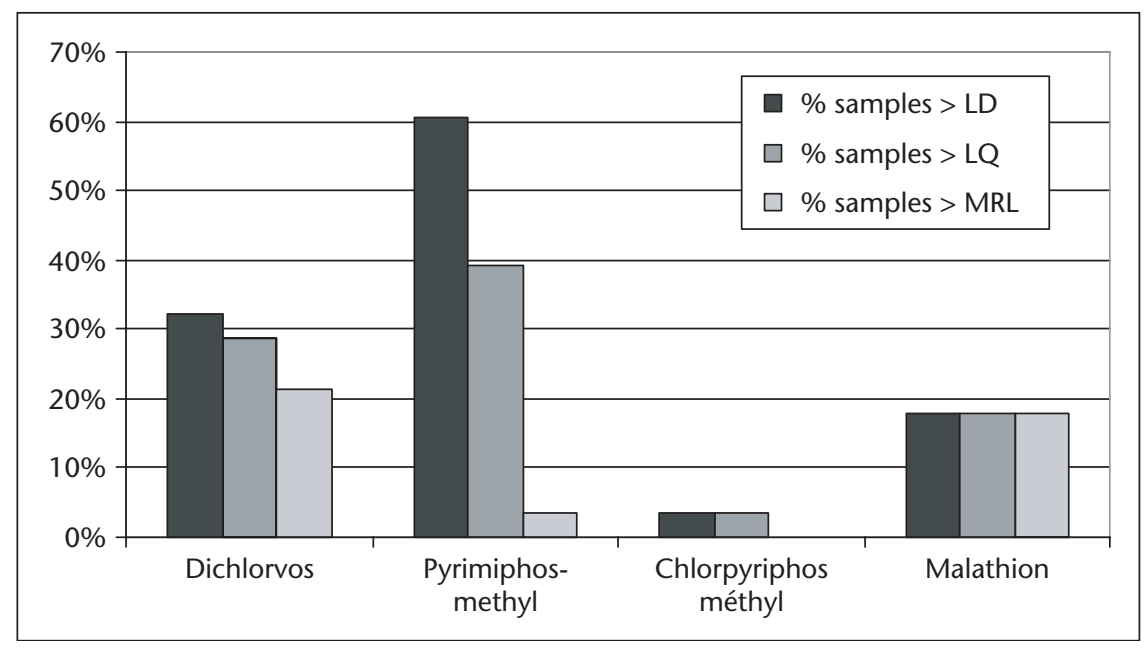

Figure 1. Statistical results on final samples.

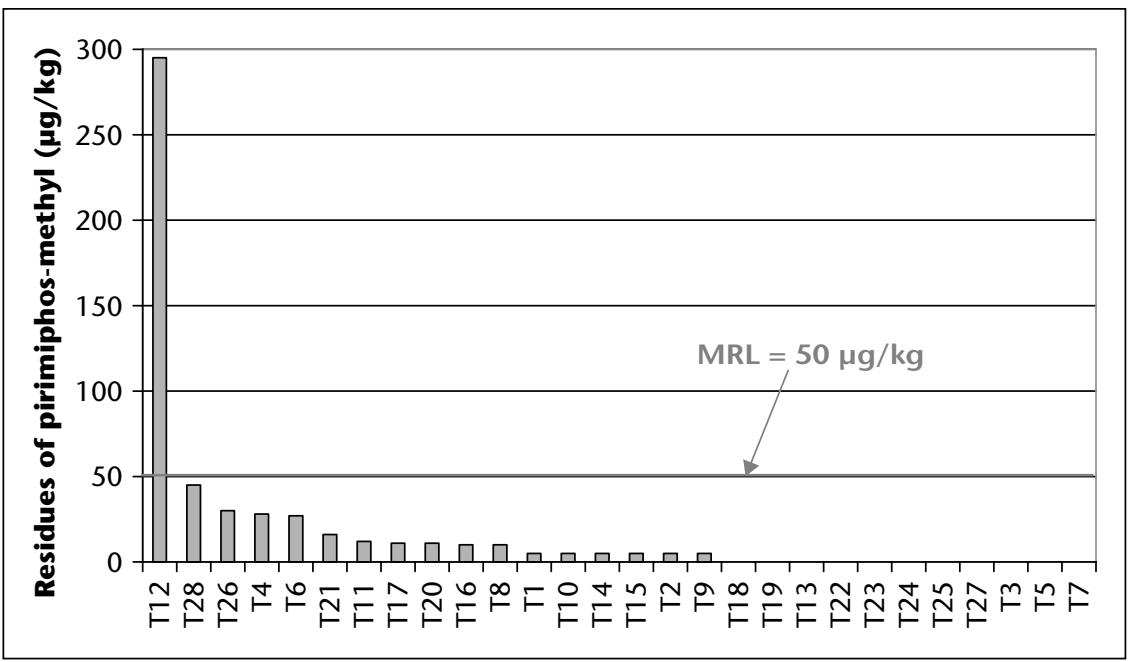

Figure 2. Individual analytical results for pirimiphos-methyl.
10 and $20 \mu \mathrm{g} / \mathrm{kg}$, and 11 below the limit of quantification.

Dichlorvos - Only one sample had a very high level (T9: $422 \mu \mathrm{g} / \mathrm{kg}$ ). Three other samples were between 20 and $50 \mu \mathrm{g} / \mathrm{kg}$. Five samples were near the MRL or below it. It wasn't detected in 19 samples.

Malathion - Only one sample had a high level 


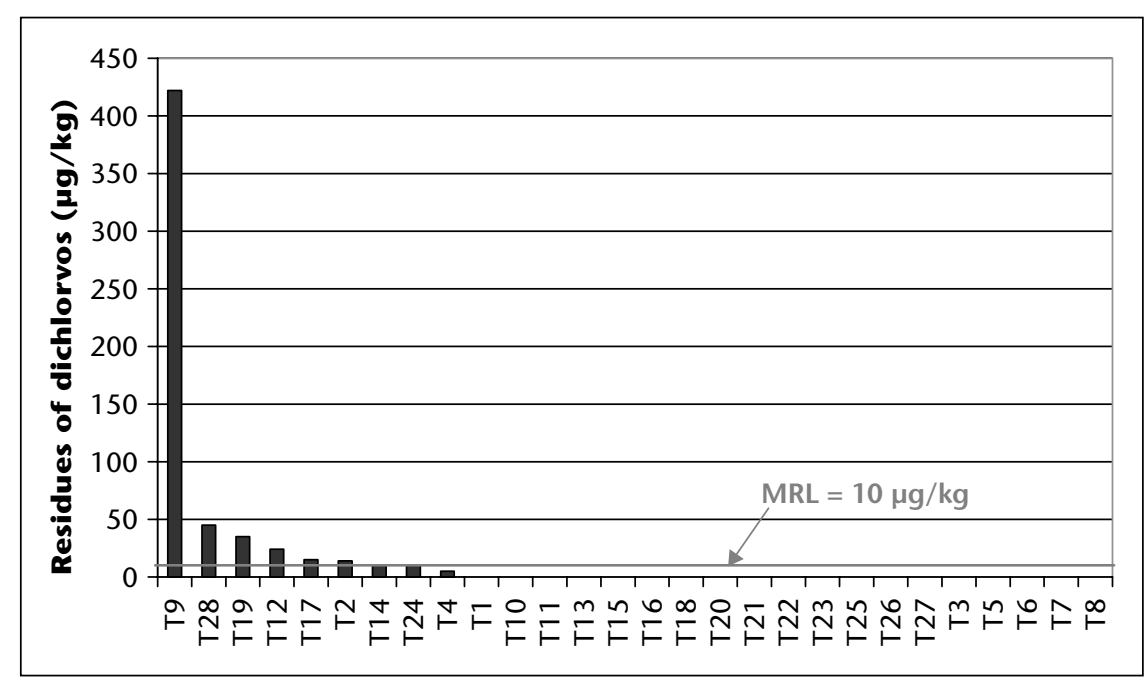

Figure 3. Individual analytical results for dichlorvos.

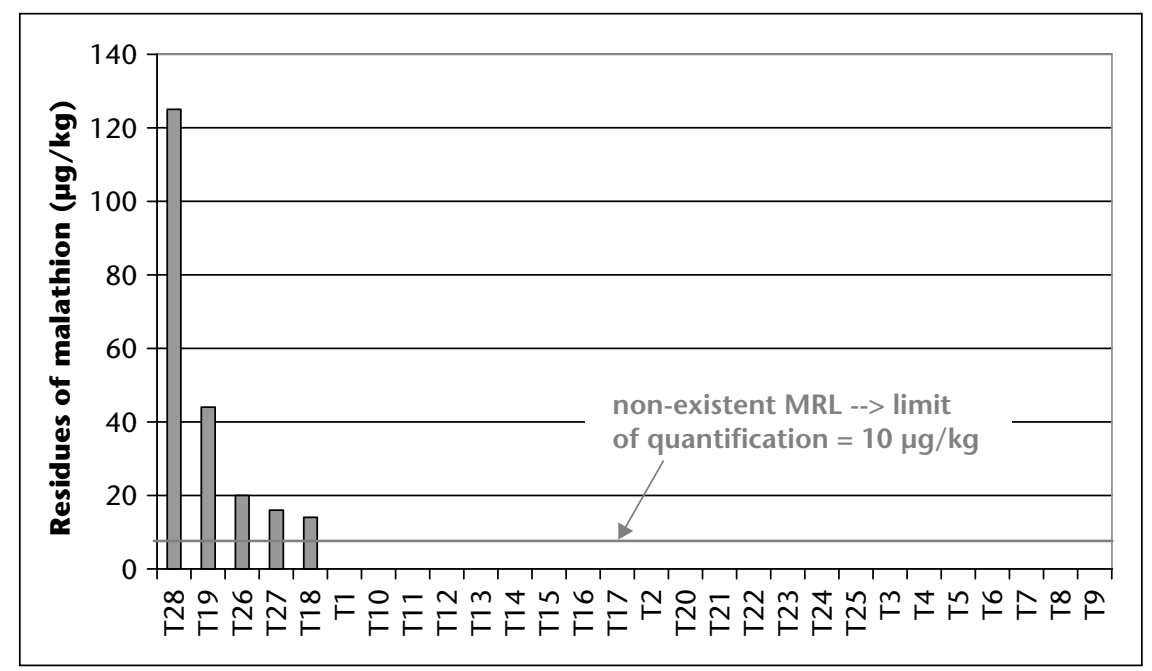

Figure 4. Individual analytical results for malathion.

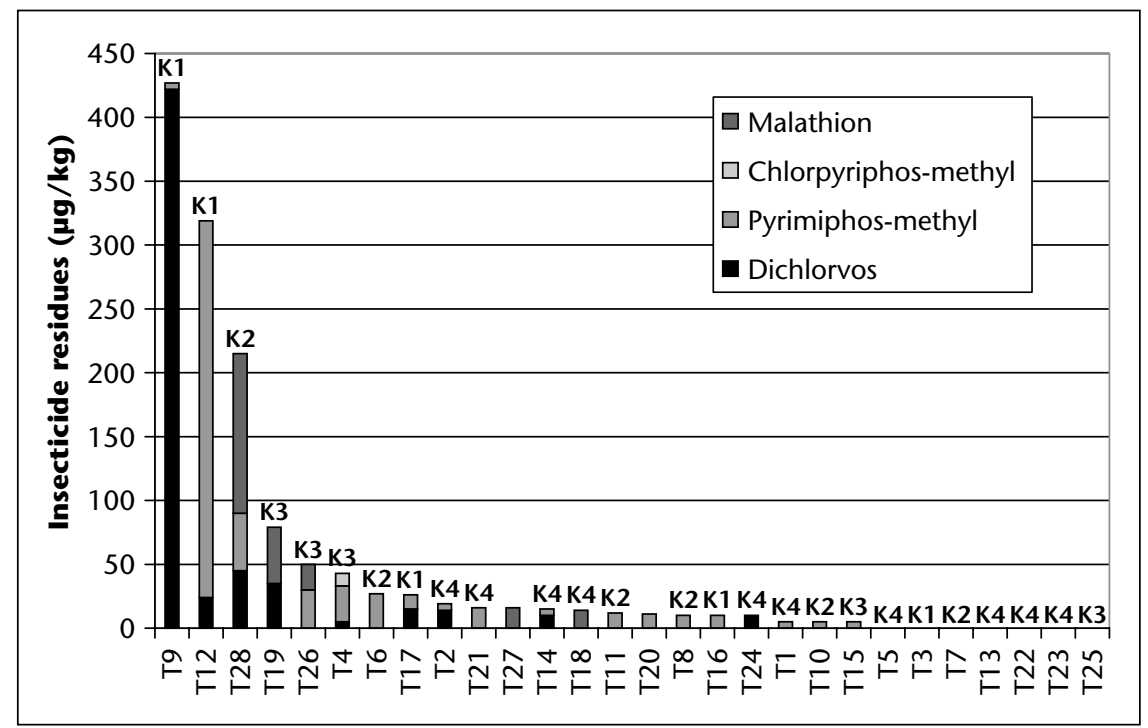

Figure 5. Distribution of the four cases $(K 1, K 2, K 3, K 4)$ for each sunflower lot, and sum of insecticide residues $(\mu \mathrm{g} / \mathrm{kg})$ for each sunflower final sample.
(T28: $125 \mu \mathrm{g} / \mathrm{kg}$ ). Four samples were between 10 and $50 \mu \mathrm{g} / \mathrm{kg}, 12$ between 10 and $20 \mu \mathrm{g} / \mathrm{kg}$. It wasn't detected in 23 samples.

In order to explain contamination, especially in the cases where a high amount of residues was detected, the "first samples" (taken at receipt of the sunflower seeds at the storage facilities) were analyzed for the batches $\mathrm{T} 4, \mathrm{~T} 12, \mathrm{~T} 19$ and T28. The insecticide residues on each "first sample" were too low to explain the residues found at the end, in the "final samples". So, the explanation had to be found in the route of the sunflower seeds inside the elevator.

Four cases leading to cross-contamination were identified:

- K1: treatment of cereals at outloading, just before outloading of sunflower seeds.

- K2: outloading of cereals, treated at their receipt, just before outloading of sunflower seeds.

- K3: storage of treated cereals in the same bin just before storage of sunflower seeds.

- K4: treatment of empty bin and of handling equipment before receiving sunflower seeds. The distribution of that different cases in our 28 sunflower seeds batches is showned in figure 5: each batch is linked to one proncipal case, even if several cases coexist within one batch.

It appears that the biggest cross-contamination occurred with the case K1. Studying the circumstances concerned with $\mathrm{K} 1$, the risk is higher when treatment of cereals at outloading is frequent or systematic. In the worst case (T9), the sunflower seeds lot were sent by lorry over a period of two weeks. Cereals were also sent during this period, and treated before outloading, and using the same outloading circuit as the sunflower (conveying belts, outloading bin).

The other cases, K2, K3, K4, can also lead to slighter cross-contaminations. For one lot, there were two cases of cross-contamination risk, and this could only have worsened the contamination.

\section{Conclusion}

Our study in real situations showed that crosscontaminations of oilseeds by post-harvest insecticide residues exist, and can sometimes lead to residues above the regulatory limits.

The highest risk of contamination appears when cereals are systematically treated at outloading, just before outloading of oilseeds, using the same conveyer circuits. The other identified cases can also lead to slighter contamination. But, silo operators have to concentrate on accumulation of several risky cases, which can worsen the contamination.

Other sources of insecticide residues can occur in storage facilities, but we couldn't check 
them in this investigation. This include leak of insecticide product by the application equipment, use of sampling equipment contaminated by pesticides. Another situation that we didn't meet in our study was crosscontamination or accidental treatment oilseeds coming storage on a farm subsequently delivered to a commercial store.

This investigation will be continued with rapeseed. This will allow us to check if rapeseed can be affected by the same cross-contamination as sunflower. The new investigation will be carried out in the new regulatory context in which dichlorvos and malathion are forbidden for cereal treatment. Thus storage operators will certainly have new grain protection strategies, which could lead to different crosscontamination risk for oilseeds.
Acknowledgements. This work was granted by ONIDOL (french oilseed chain organization) and FEDIOL (European oil and protein meal industry federation), with additional technical support of FNCG (French national oil industry federation), ITERG (French technical institute for oil industry), FNA (Fédération du Négoce Agricole), Coop de France-Métiers du grain, SAIPOL and CARGILL.

\section{REFERENCES}

1. WATTERS FL, NOWICKI TW. Uptake of bromophos by stored rapeseed. J Econom Entomol 1982; 75(2): 261-4.

2. WHITE NDG, NOWICKI TW, WATTERS FL. Comparison of fenitrothion and malathion for treatment of plywood and galvanized steel surfaces for control of the red flour beetle and the rusty grain beetle. I Econom Entomol 1983; 76(4): 856-63.

3. WHITE NDG, NOWICKI TW. Effects of temperature and duration of storage on the degradation of malathion residues in dry rapeseed. I Stored Prod Res 1985; 21(3): 111-4.

4. DAUGUET S, LACOSTE F, TICOT B, ET AL. La filière oléagineuse se mobilise autour de la problématique des résidus d'insecticides. OCL 2006; 13(6): 373-7.

5. DAUGUET S, EVRARD I, FRITSCH J, LOISON JP. Accumulation of pesticide residues in oil during the storage of rapeseed. $12^{\text {th }}$ International Rapeseed Congress, Wuhan Hubei, China, March 26-30 2007. 